\title{
Focus on ADF/Cofilin: Beyond Actin Cytoskeletal Regulation
}

\author{
Cheng-Han Tsai and Yi-Jang Lee \\ Department of Biomedical Imaging and Radiological Sciences, School of Biomedical Science and Engineering, \\ National Yang-Ming University, Taipei, Taiwan \\ Correspondence should be addressed to Yi-Jang Lee, yjlee2@ym.edu.tw
}

Received 8 November 2011; Accepted 8 December 2011

Academic Editors: V. M. Golubovskaya and A. A. Minin

Copyright ( 92012 C.-H. Tsai and Y.-J. Lee. This is an open access article distributed under the Creative Commons Attribution License, which permits unrestricted use, distribution, and reproduction in any medium, provided the original work is properly cited.

\begin{abstract}
Actin depolymerizing factor (ADF)/cofilin, an actin binding protein ubiquitously expressed in a variety of organisms, is required for regulation of actin dynamics. The activity of $\mathrm{ADF} /$ cofilin is dependent on serine 3 phosphorylation by LIM kinase (LIMK), which is regulated by the Rho small GTPase signaling pathway. ADF/cofilin is strongly associated with several important cell biological functions, including cell cycle, morphological maintenance and locomotion. These functions affect several biological events, including embryogenesis, oncology, nephropathy and neurodegenerations. Here, we focus on the biochemical and pathophysiological role of $\mathrm{ADF} /$ cofilin in mammals.
\end{abstract}

\section{Introduction}

$\mathrm{ADF} /$ cofilin has been reported to be involved in several cellular functions via regulation of actin dynamics. For instance, $\mathrm{ADF} /$ cofilin is required for actin reorganization at the contractile ring for cytokinesis and is essential for cell cycle progression. ADF/cofilin regulates actin dynamics through a depolymerization or severing of actin filaments. The only known mechanism for regulating the activity of ADF/cofilin activity is protein phosphorylation. ADF/cofilin becomes inactive when it is phosphorylated at serine 3 residue by LIM kinase (LIMK) or testis-specific kinase (TESK) 1 and 2 [1-3]. For LIMK, a series of signal transduction pathway for $\mathrm{ADF} /$ cofilin activity is primarily controlled by Rho family of small GTPase. Cells stimulated by growth factors lead to activation of the receptor tyrosine kinase (RTK) that recruits Rho small GTPase and Rho-associated protein kinase (ROCK) to phosphorylate LIM kinase and subsequent ADF/cofilin [4]. Also, dephosphorylation of ADF/cofilin is mediated by slingshot ( $\mathrm{SSH}$ ) phosphatase, chronophin (CIN) phosphatase, and protein phosphatase 1 and 2A (PP1 and PP2A) [5]. In addition to protein phosphorylation, the activity of ADF/cofilin is also regulated by intracellular $\mathrm{pH}$ and its association with phosphatidyl inositol bisphosphate (PIP2) [6].
Recent studies have shown that the activity of ADF/ cofilin is increased at the telophase of mitosis to regulate the dynamics of actomyosin-based contractile ring and maintain the cleavage furrow for cell division [7, 8]. In addition to mitotic phase, optimal expression of $\mathrm{ADF} / \mathrm{cofilin}$ is also critical for G1 to $\mathrm{S}$ phase progression. Forced expression of $\mathrm{ADF} /$ cofilin can result in G1 phase arrest through destabilization of actin cytoskeleton and upregulation of cell cycle inhibitor $\mathrm{p} 27^{\mathrm{kip} 1}$ [9].

$\mathrm{ADF} /$ cofilin is involved in migration, locomotion and metastasis of cancerous cells. It has been reported that $\mathrm{ADF} /$ cofilin is associated with the advanced tumors that are prone to invasiveness and metastasis [10]. Therefore, targeting on ADF/cofilin is considered as one of the therapeutic strategies for cancer treatment $[11,12]$. On the other hand, the inhibitory role of $\mathrm{ADF} /$ cofilin on cancer progression has also been reported because ectopic-expressed ADF/cofilin can suppress the motility and proliferation of human cancer cells $[11,13]$. Thus, it remains controversial about the role of $\mathrm{ADF} / \mathrm{cofilin}$ on tumorigenesis, and profound investigation would be required.

Taken together, ADF/cofilin is not only essential for cell motility but also the cell cycle progression. The phosphorylated state of $\mathrm{ADF} /$ cofilin affects the activity and stability of this protein on actin cytoskeletal organization 
and subsequent cell physiology [14]. Furthermore, recent studies have addressed the importance of $\mathrm{ADF} /$ cofilin on neurology and nephrology $[15,16]$. In this paper, we will discuss the biochemical mechanisms of ADF/cofilin. Also, the role of $\mathrm{ADF} /$ cofilin on mediating the physiology and pathology in neurology, nephrology, and oncology will also be elucidated.

\section{Basic Functions of ADF/Cofilin}

2.1. Actin Dynamics by ADF/Cofilin and Other Actin-Binding Proteins. The ADF/cofilin family includes three isoforms of proteins, the so-called cofilin-1, cofilin-2, and destrin (also named ADF). They share similar biochemical functions on regulating the actin dynamics. Cofilin-1 is ubiquitously expressed in nonmuscle tissues of various organisms, while cofilin-2 is only expressed in muscle. ADF is also expressed in non-muscle tissues, but the level is about $5 \%$ to $10 \%$ of cofilin-1 [17]. The name of cofilin was obtained from its binding ability on monomeric actin embedded in the actin filaments (Co-filamentous with actin) with a $1: 1$ stoichiometry [6].

Regulation of actin dynamics by ADF/cofilin on is largely dependent on the concentration of $\mathrm{ADF} /$ cofilin in vitro and in vivo [6]. Lower concentration of $\mathrm{ADF} /$ cofilin exhibits higher binding affinity to ADP-bound actin in the filaments. The consequence is to promote depolymerization from the pointed end of actin filaments. On the contrary, higher level of ADF/cofilin can stabilize the actin filaments and even initiate the nucleation of G-actins, which lead to elongation and branched by profilin or Arp $2 / 3$ complex, respectively $[6,18,19]$. Therefore, the level of ADF/cofilin can influence the actin dynamics with a biphasic manner that may trigger different effects on cell physiology [20].

$\mathrm{ADF} /$ cofilin not only severs or depolymerizes actin filaments but also cooperates with other actin-binding proteins to assemble stress fiber and lamellipodia formed by filamentous actin [21, 22]. Formation of stress fibers and lamellipodia is regulated by Rho signaling pathway, which mediates various downstream kinase activity to phosphorylate ADF/cofilin, tropomyosin, and light chain of myosin II (MLC) [23]. For stress fibers formation through Rho, ADF/cofilin is inactivated through phosphorylation by LIMK1, while myosin II becomes active via phosphorylation by myosin light chain kinase (MLCK). For lamellipodia formation at the leading edge, the $\mathrm{ADF} /$ cofilin activity is increased by dephosphorylation through phosphatases. By contrast, the myosin II activity is decreased after dephosphorylation [24-26]. Therefore, ADF/cofilin alone is not sufficient to mediate actin cytoskeletal organization. A cooperation of $\mathrm{ADF} /$ cofilin with other actin-regulating proteins is required for normal mechanical functions in cells.

2.2. The Signal Transduction Pathways for Regulation of ADF/ Cofilin Activity and Actin Filaments Reorganization. The reorganization of actin filament is triggered by extracellular signals such as growth factors, chemoattractants, or toxins that may bind to surface receptors. These receptors turn on a series of signal transduction pathways, such as Aktphosphoinositide 3-kinase (PI3K) and Ras-Erk cascades after mitogenic stimulations [27-30]. Rho small GTPase family and its downstream effectors, including Rho-associated kinase (ROCK) and p21-activated kinase (PAK), are responsible for forming and organizing the actin cytoskeleton into filopodia, lamellipodia, and stress fibers. Both activated ROCK and PAK phosphorylates activate LIM kinase $(1 / 2)$ and then inactivate ADF/cofilin via phosphorylation at serine 3 residue $[1,31,32]$. Another kinase named TESK can inactivate $\mathrm{ADF} / \mathrm{cofilin}$ through phosphorylation at the same residue [2]. The protein kinase domain of TESK is similar to that of LIM kinase, although their overall structures are distinct. It has been demonstrated that regulation of $\mathrm{ADF} /$ cofilin activity by TESK is dependent on integrin [2]. Thus, at least two parallel pathways may exist for regulation of $\mathrm{ADF} /$ cofilin activity $[2,33]$. In contrast, slingshot ( $\mathrm{SSH})$ phosphatase and chronophin (CIN) have been identified to activate $\mathrm{ADF} / \mathrm{cofilin}$ by dephosphorylating serine 3 residue and suppressing the assembly of actin filaments [34, 35].

Although the activity of $\mathrm{ADF} /$ cofilin on actin regulation has been widely studied, the expression level of ADF/cofilin is less reported. We have found that $\mathrm{ADF} /$ cofilin is accumulated in confluent cells, and overexpression of ADF/cofilin causes G1 phase arrest in a variety of cell lines [9]. A recent report shows that the protein stability of $\mathrm{ADF} /$ cofilin is dependent on the phosphorylation of tyrosine 68 residue by $\mathrm{v}$-src protooncogene [36]. Overexpression of $\mathrm{v}$-src has been reported to influence F-actin organization and cell spreading in cancerous cells $[37,38]$. It is of interest to further investigate whether $\mathrm{ADF} /$ cofilin is required for v-srcmediated cell proliferation and migration.

\section{ADF/Cofilin in Cell Cycle and Embryogenesis}

3.1. ADF/Cofilin and Cell Cycle. The cell cycle progression is accompanied by a reorganization of actin cytoskeleton that mediates the morphological change and cell spreading for conveying the extracellular stimuli to intracellular signal transduction. It has been reported that $\mathrm{ADF} /$ cofilin also plays an important role during cell cycle [39, 40]. Cell anchorage and spreading are observed in the interphase, while the morphology becomes round and loss of attachment from the substratum after cells enter the mitotic phase $[41,42]$. In the mitotic phase, actin filaments are also involved in chromosome segregation by anchoring onto the microtubules [43]. The effects of ADF/cofilin on cell cycle include (1) providing the mechanical force for division of daughter cells during cytokinesis and (2) regulating the actin dynamics for signal transductions in the G1 phase $[44,45]$. To regulate the actin dynamic during mitosis, the $\mathrm{ADF} /$ cofilin activity is suppressed by LIMK 1 and 2 in the metaphase $[46,47]$, but reactivated by slingshot homolog 1 (SSH-1) phosphatase after the telophase [7]. Overexpression of LIMK1 has also been reported to increase the aneuploidy and chromosomal instability in prostate cancer, suggesting that $\mathrm{ADF} /$ cofilin activity is importance for cell division [48]. We have found that forced expression of cofilin-1 leads to 
G1 phase arrest [39]. Recently, we also found that cofilin-1 expression is lowest in G1 phase compared to other cell cycle phase (unpublished data). Thus, the expressions as well as the activity regulation of $\mathrm{ADF} / \mathrm{cofilin}$ are both essential for the cell cycle progression.

Growth factors affect the cell proliferation by stimulating different signal transduction pathways, including Akt -PI3K, Ras-MAPK (mitogen activated protein kinase), and small GTPase family, Rho, Rac and Cdc42 [49-51]. It has been reported that the upregulation of cyclin D1, suppression of $\mathrm{p} 21^{\text {cip1/wafl }}$, and hyperphosphorylation of retinoblastoma protein $(\mathrm{Rb})$ are involved in $\mathrm{G} 1$ to $\mathrm{S}$ phase transition via activation of Ras-MAPK and small GTPase family pathways $[52,53]$. Upon stimulation, the activity of $\mathrm{ADF} /$ cofilin is ablated by the Rho signaling pathway for actin cytoskeletal reorganization in the G1/S phase progression $[1,9,54]$. However, the MAPK activity was not influenced by overexpressed cofilin and cytochalasin B, a routinely used actin targeting agent (unpublished data), suggesting that directly destabilization of actin cytoskeleton is sufficient to ablate the cell cycle progression even the cells are stimulated by mitogens.

3.2. ADF/Cofilin and Embryogenesis. The embryogenesis is associated with cell cycle progression to become a multicellular entity [55]. The developing stages of embryogenesis include zygotes, morula, blastomeres, and gastrula. The zygote is the first stage of embryogenesis followed by the morula, blastomeres (also called blastocyst in mammalian), and gastrula in the end. After gastrula, the developments of ectoderm, mesoderm, and endoderm are initiated by rapid cell division. Actin cytoskeletal organization is involved in cell divisions for determining the cell polarity, orientation, and proliferation in embryos, as well as the development of cell walls in higher plants [56, 57]. Deactivation of $\mathrm{ADF} /$ cofilin is critical for the compaction stage, which is a process in 8-cell stage of embryos [58]. The asymmetry of embryos is first observed in 8-cell stage when operates the polarization, flatness, and adherent junction of embryos within blastomeres. These processes can only be promoted when the expression of $\mathrm{ADF} /$ cofilin is silenced during this stage. Knockdown or inactivation of ADF/cofilin using siRNA or site-directed mutagenesis accelerates the compaction of embryos, respectively [58]. This report demonstrated that the level of ADF/cofilin needs to be precisely regulated for cell cycle progression and embryogenesis.

\section{ADF/Cofilin in Neurology, Nephrology, and Cancer}

$\mathrm{ADF} /$ cofilin also plays an important role on neuron development, kidney functions, and cancer development. $\mathrm{ADF} /$ cofilin has been identified as a biomarker of Alzheimer's disease [59]. In addition, ADF/cofilin is regarded a critical molecule for providing the mechanical force on the filter barrier system in podocytes, which are specialized visceral epithelial cells in a glomerulus [16]. Also, ADF/cofilin may be involved in advanced human cancers with the metastatic property [11]. We briefly summarize the biochemical and biological role of $\mathrm{ADF} /$ cofilin on these human disorders.

4.1. ADF/Cofilin and Alzheimer Disease. It has been reported that the appearance of cofilin-actin rod-enriched inclusion bodies is a pathological feature widely existed in a broad spectrum of neurodegenerative diseases $[15,59]$. Cofilinactin rods are rapidly formed in response to neural stress [60]. ADF/cofilin can be activated by the neurodegenerative stimuli, such as aggregated beta-amyloid $(\mathrm{A} \beta)$ and oxidative stress. $\mathrm{ADF} /$ cofilin abnormally aggregates punctuates and rod-like linear arrays along the striated neuropil threads, which is a conventional feature of Alzheimer disease [61, 62]. Furthermore, ADF/cofilin undergoes phosphorylation and dephosphorylation stimulated by $\mathrm{A} \beta_{1-40}$ and $\mathrm{A} \beta_{1-42}$ in neurons, respectively [63]. The phosphoregulation of $\mathrm{ADF} /$ cofilin protein further influence the formation of rodlike actin bundles and the accumulation of phosphorylated tau protein, a critical pathological characteristic of Alzheimer disease. Hence, $\mathrm{ADF} /$ cofilin is likely a mediator to cause Alzheimer disease by increasing several transport defects in neurons responding to environmental stress [63]. Taken together, $\mathrm{ADF} /$ cofilin is prominent in hippocampal and cortical neurites of the postmortem brains of Alzheimer's patients, especially in neuritis with amyloid beta depositions [61].

4.2. ADF/Cofilin Is Critical for the Filter Barrier System of Kidney. The role of ADF/cofilin in nephrology has also been defined in last decade. Currently, it is believed that the active form of $\mathrm{ADF} /$ cofilin is not only critical for maintaining the morphology of podocytes but also required for the development of podocytes [64]. Podocytes are high-specialized and terminal-differentiated epithelial cell located at the outer aspect of the glomerular basement membrane to prevent the leakage of urine protein, maintenance of glomerular capillary loops integrity, and serve as a barrier to against the intracapillary hydrostatic pressure $[65,66]$. Podocytes consist of three segments with different functions: a cell body, major processes, and foot processes. The processes are mainly organized by actin dynamics [67]. The actin filamental-mediated mechanical force and focal adhesion in podocytes are important for maintaining the functions of selective filtration barrier of kidney. Foot processes (FP) have three functionally membrane domains: the apical membrane domain, the slit diaphragm (SD), and the basal membrane domain (or sole plate) associated with glomerular basement membrane (GBM). These structures form the adherent junctions and barrier to filtrate protein and albumin from blood vessels and capillaries around the glomerulus [68, 69]. Also, the actin cytoskeleton is critical for all three functional domains $[16,67]$. Inactivation of $\mathrm{ADF} /$ cofilin by serine-3 phosphorylation is reported to be correlated with proteinuria in zebra fish, mice, and humans [70]. Proteinuria is a type of nephropathy caused by the injury of three cell types including mesangial cells, podocytes, and endothelial cells in glomerular units. Degeneration of podocytes is a primary event in the development of chronic renal failure and proteinuria. Activated ADF/cofilin 
is well distributed in normal podocytes, but inactivated (phosphorylated) ADF/cofilin can be found throughout misfunctional podocyte cells [70]. Of interest, ADF/cofilin can be activated for actin filamental reorganization through receptor tyrosine kinase activation, the so-called NephrinNeph1 receptor complex on the membranes of podocytes [64]. In addition to ADF/cofilin, $\alpha$-actinin-4 [71], nephrin [72], and podocin [73] are also involved in regulating the dynamics of actin cytoskeleton and are important for the functions of podocytes on renal filtration.

4.3. ADF/Cofilin in Cancer Growth and Metastasis. The features of cancers include uncontrollable growth and distant dissemination. They are important index for design of cancer therapeutic strategies. The actin cytoskeletal reorganization is involved in these phenotypes, and several toxins targeting on the networks of actin filaments have been reported to efficiently inhibit cell cycle progression and induce apoptosis in cancer cells $[74,75]$. For instance, cucurbitacins [76, 77] derived from medicinal plants have many isoforms and they are widely used in cancer therapy because they disrupt the formation of filamentous actin and subsequently cause G2/M phase arrest and apoptosis in breast cancers [78], glioblastoma (GBM) [79], and prostate cancer [80]. In addition, a series of actin toxins that display highly antitumor effects have been used for anticancer researches by interfering the actin polymerization and depolymerization. For instance, latrunculin A (LA) has been used for inhibition of gastric cancers [81]; cytochalasin B (CB) is able to control the growth of lung cancers [82], and jasplakinolide (JP) can inhibit the prostate cancer and Lewis lung cancer [83]. LA can induce cofilin-1 phosphorylation, but the mechanisms are largely unknown [84]. In our lab, we have demonstrated that overexpressed cofilin-1 enhances radiosensitivity and G1 phase arrest in human lung cancer cells $[39,85]$. Overexpressed cofilin-1 is normally phosphorylated and is able to repress the expression of several DNA repair proteins including Rad51, Ku70, and Ku80. For the G1 phase arrest, cofilin-1 may upregulate the cell cycle inhibitor p27 $7^{\text {kip } 1}$ through transcriptional and translational mechanisms [9]. Whether cofilin-1 can be used for gene therapy to avoid high toxicity of actin toxins is of interest to further investigate.

The distant metastasis of tumor cells is the primary cause of mortality. Metastasis and invasion are caused by multiple processes that are associated with the reorganization of actin filament as well as actin regulatory proteins, such as ADF/cofilin, Arp2/3 (actin-related proteins 2/3), and WASP (Wiskott-Aldrich syndrome protein) $[18,20]$. The cancer migration and metastasis are suppressed when $\mathrm{ADF} /$ cofilin is silenced by the small interfering RNA (siRNA) [11, 86, 87]. Because overexpression of LIMK1 has been reported in different types of human cancers, it seems reasonable that $\mathrm{ADF} /$ cofilin should be activated in cancer metastasis. [88-91]. On the other hand, overexpression of ADF/cofilin inhibits motility and invasion in different types of cancer cells $[13,92]$. Thus, the role of $\mathrm{ADF} /$ cofilin on invasion and metastasis required further investigation. In addition, in the epidermal-growth-factor- (EGF-) induced migration, the activity of $\mathrm{ADF} / \mathrm{cofilin}$ is regulated by phospholipid
PtdIns(4,5)P2 (PIP2) and phospholipase C $\gamma$ (PLC $\gamma)$ that induce transient activity of ADF/cofilin last for 60 second after EGF stimulation [93]. At least two signal transduction pathways may regulate the activity of $\mathrm{ADF} / \mathrm{cofilin}$ through phosphorylation on serine 3 residue during cell migration.

\section{Conclusion}

$\mathrm{ADF} /$ cofilin regulates actin dynamics and influences various biological functions in different cell types. Deregulation of $\mathrm{ADF} /$ cofilin in amount or activity may be associated with human diseases. The activity and stability of $\mathrm{ADF} /$ cofilin have been reported to be controlled by the Rho small GTPase and Src signaling pathway, respectively. Thus, targeting on these signaling pathways would be one of the important strategies for cancer treatment. ADF/cofilin is also associated with Alzheimer's diseases and proteinuria, while it is a cause or consequence of these disorders required further investigations. Although it is believed that $\mathrm{ADF} /$ cofilin is associated with cancer development, how $\mathrm{ADF} /$ cofilin participates malignancy is not fully understood. We expect that the pathophysiological function of $\mathrm{ADF} /$ cofilin will be better understood by more comprehensive studies in the future.

\section{Acknowledgments}

This work was granted by Yen Tjing Ling Medical Foundation (CI-97-10) and National Science Council of Taiwan (NSC99-2314-B-010-029-MY3).

\section{References}

[1] O. Bernard, "Lim kinases, regulators of actin dynamics," International Journal of Biochemistry and Cell Biology, vol. 39, no. 6, pp. 1071-1076, 2007.

[2] J. Toshima, J. Y. Toshima, T. Amano, N. Yang, S. Narumiya, and K. Mizuno, "Cofilin phosphorylation by protein kinase testicular protein kinase 1 and its role in integrin-mediated actin reorganization and focal adhesion formation," Molecular Biology of the Cell, vol. 12, no. 4, pp. 1131-1145, 2001.

[3] J. Toshima, J. Y. Toshima, K. Takeuchi, R. Mori, and K. Mizuno, "Cofilin phosphorylation and actin reorganization activities of testicular protein kinase 2 and its predominant expression in testicular sertoli cells," Journal of Biological Chemistry, vol. 276, no. 33, pp. 31449-31458, 2001.

[4] M. Kobayashi, M. Nishita, T. Mishima, K. Ohashi, and K. Mizuno, "MAPKAPK-2-mediated LIM-kinase activation is critical for VEGF-induced actin remodeling and cell migration," EMBO Journal, vol. 25, no. 4, pp. 713-726, 2006.

[5] T. Takuma, T. Ichida, N. Yokoyama, S. Tamura, and T. Obinata, "Dephosphorylation of cofilin in parotid acinar cells," Journal of Biochemistry, vol. 120, no. 1, pp. 35-41, 1996.

[6] J. R. Bamburg and B. W. Bernstein, "ADF/cofilin," Current Biology, vol. 18, no. 7, pp. R273-R275, 2008.

[7] N. Kaji, K. Ohashi, M. Shuin, R. Niwa, T. Uemura, and K. Mizuno, "Cell cycle-associated changes in Slingshot phosphatase activity and roles in cytokinesis in animal cells," Journal of Biological Chemistry, vol. 278, no. 35, pp. 33450-33455, 2003. 
[8] R. M. Warn and R. Magrath, "F-actin distribution during the cellularization of the Drosophila embryo visualized with FLphalloidin," Experimental Cell Research, vol. 143, no. 1, pp. 103-114, 1983.

[9] C. H. Tsai, S. J. Chiu, C. C. Liu et al., "Regulated expression of cofilin and the consequent regulation of p27 kip1 are essential for G1 phase progression," Cell Cycle, vol. 8, no. 15, pp. 23652374, 2009.

[10] W. Wang, G. Mouneimne, M. Sidani et al., "The activity status of cofilin is directly related to invasion, intravasation, and metastasis of mammary tumors," Journal of Cell Biology, vol. 173, no. 3, pp. 395-404, 2006.

[11] W. Wang, R. Eddy, and J. Condeelis, "The cofilin pathway in breast cancer invasion and metastasis," Nature Reviews Cancer, vol. 7, no. 6, pp. 429-440, 2007.

[12] M. Quintela-Fandino, E. Arpaia, D. Brenner et al., "HUNK suppresses metastasis of basal type breast cancers by disrupting the interaction between PP2A and cofilin-1," Proceedings of the National Academy of Sciences of the United States of America, vol. 107, no. 6, pp. 2622-2627, 2010.

[13] Y. J. Lee, D. J. Mazzatti, Z. Yun, and P. C. Keng, "Inhibition of invasiveness of human lung cancer cell line H1299 by overexpression of cofilin," Cell Biology International, vol. 29, no. 11, pp. 877-883, 2005.

[14] R. Nagaoka, H. Abe, and T. Obinata, "Site-directed mutagenesis of the phosphorylation site of cofilin: its role in cofilin-actin interaction and cytoplasmic localization," Cell Motility and the Cytoskeleton, vol. 35, no. 3, pp. 200-209, 1996.

[15] J. R. Bamburg, B. W. Bernstein, R. C. Davis et al., "ADF/Cofilin-actin rods in neurodegenerative diseases," Current Alzheimer Research, vol. 7, no. 3, pp. 241-250, 2010.

[16] K. Berger and M. J. Moeller, "Cofilin-1 in the podocyte: a molecular switch for actin dynamics," International Urology and Nephrology, vol. 43, no. 1, pp. 273-275, 2011.

[17] M. K. Vartiainen, T. Mustonen, P. K. Mattila et al., "The three mouse actin-depolymerizing factor/cofilins evolved to fulfill cell-type-specific requirements for actin dynamics," Molecular Biology of the Cell, vol. 13, no. 1, pp. 183-194, 2002.

[18] L. Blanchoin, T. D. Pollard, and R. D. R. D. Mullins, "Interactions of ADF/cofilin, Arp2/3 complex, capping protein and profilin in remodeling of branched actin filament networks," Current Biology, vol. 10, no. 20, pp. 1273-1282, 2000.

[19] M. Van Troys, L. Huyck, S. Leyman, S. Dhaese, J. Vandekerkhove, and C. Ampe, "Ins and outs of ADF/cofilin activity and regulation," European Journal of Cell Biology, vol. 87, no. 8-9, pp. 649-667, 2008.

[20] B. W. Bernstein and J. R. Bamburg, "ADF/Cofilin: a functional node in cell biology," Trends in Cell Biology, vol. 20, no. 4, pp. 187-195, 2010.

[21] M. Oser and J. Condeelis, "The cofilin activity cycle in lamellipodia and invadopodia," Journal of Cellular Biochemistry, vol. 108, no. 6, pp. 1252-1262, 2009.

[22] S. Kurita, E. Gunji, K. Ohashi, and K. Mizuno, "Actin filaments-stabilizing and -bundling activities of cofilinphosphatase Slingshot-1," Genes to Cells, vol. 12, no. 5, pp. 663-676, 2007.

[23] N. Marcoux and K. Vuori, "EGF receptor activity is essential for adhesion-induced stress fiber formation and cofilin phosphorylation," Cellular Signalling, vol. 17, no. 11, pp. 14491455, 2005.

[24] N. S. Bryce, G. Schevzov, V. Ferguson et al., "Specification of actin filament function and molecular composition by tropomyosin isoforms," Molecular Biology of the Cell, vol. 14, no. 3, pp. 1002-1016, 2003.
[25] P. Gunning, G. O’Neill, and E. Hardeman, "Tropomyosinbased regulation of the actin cytoskeleton in time and space," Physiological Reviews, vol. 88, no. 1, pp. 1-35, 2008.

[26] K. Katoh, Y. Kano, M. Amano, K. Kaibuchi, and K. Fujiwara, "Stress fiber organization regulated by MLCK and Rhokinase in cultured human fibroblasts," American Journal of Physiology, vol. 280, no. 6, pp. C1669-C1679, 2001.

[27] J. R. Molina and A. A. Adjei, "The Ras/Raf/MAPK pathway," Journal of Thoracic Oncology, vol. 1, no. 1, pp. 7-9, 2006.

[28] W. Kolch, "Coordinating ERK/MAPK signalling through scaffolds and inhibitors," Nature Reviews Molecular Cell Biology, vol. 6, no. 11, pp. 827-837, 2005.

[29] J. Paez and W. R. Sellers, "PI3K/PTEN/AKT pathway. A critical mediator of oncogenic signaling," Cancer Treatment and Research, vol. 115, pp. 145-167, 2003.

[30] G. H. Wabnitz, G. Nebl, M. Klemke, A. J. Schröder, and Y. Samstag, "Phosphatidylinositol 3-kinase functions as a Ras effector in the signaling cascade that regulates dephosphorylation of the actin-remodeling protein cofilin after costimulation of untransformed human T lymphocytes," Journal of Immunology, vol. 176, no. 3, pp. 1668-1674, 2006.

[31] D. T. Denhardt, "Signal-transducing protein phosphorylation cascades mediated by Ras/Rho proteins in the mammalian cell: the potential for multiplex signalling," Biochemical Journal, vol. 318, no. 3, pp. 729-747, 1996.

[32] S. H. Zigmond, "Signal transduction and actin filament organization," Current Opinion in Cell Biology, vol. 8, no. 1, pp. 66-73, 1996.

[33] S. Arber, F. A. Barbayannis, H. Hanser et al., "Regulation of actin dynamics through phosphorylation of cofilin by LIMkinase," Nature, vol. 393, no. 6687, pp. 805-809, 1998.

[34] T. Y. Huang, C. Dermardirossian, and G. M. Bokoch, "Cofilin phosphatases and regulation of actin dynamics," Current Opinion in Cell Biology, vol. 18, no. 1, pp. 26-31, 2006.

[35] R. Niwa, K. Nagata-Ohashi, M. Takeichi, K. Mizuno, and T. Uemura, "Control of actin reorganization by slingshot, a family of phosphatases that dephosphorylate ADF/cofilin," Cell, vol. 108, no. 2, pp. 233-246, 2002.

[36] Y. Yoo, H. J. Ho, C. Wang, and J. L. Guan, "Tyrosine phosphorylation of cofilin at Y68 by v-Src leads to its degradation through ubiquitin-proteasome pathway," Oncogene, vol. 29, no. 2, pp. 263-272, 2010.

[37] M. De Graauw, I. Tijdens, M. B. Smeets, P. J. Hensbergen, A. M. Deelder, and B. Van De Water, "Annexin A2 phosphorylation mediates cell scattering and branching morphogenesis via cofilin activation," Molecular and Cellular Biology, vol. 28, no. 3, pp. 1029-1040, 2008.

[38] U. Rescher, C. Ludwig, V. Konietzko, A. Kharitonenkov, and V. Gerke, "Tyrosine phosphorylation of annexin A2 regulates Rho-mediated actin rearrangement and cell adhesion," Journal of Cell Science, vol. 121, no. 13, pp. 2177-2185, 2008.

[39] Y. J. Lee and P. C. Keng, "Studying the effects of actin cytoskeletal destabilization on cell cycle by cofilin overexpression," Molecular Biotechnology, vol. 31, no. 1, pp. 1-10, 2005.

[40] G. C. Bellenchi, C. B. Gurniak, E. Perlas, S. Middei, M. Ammassari-Teule, and W. Witke, "N-cofilin is associated with neuronal migration disorders and cell cycle control in the cerebral cortex," Genes and Development, vol. 21, no. 18, pp. 2347-2357, 2007.

[41] M. S. Crane, J. B. Clarke, and D. B. Thomas, "Cell cycle dependent changes in morphology. Studies with a cold sensitive mutant of Chinese hamster ovary cells," Experimental Cell Research, vol. 107, no. 1, pp. 89-94, 1977. 
[42] A. G. Clark and E. Paluch, "Mechanics and regulation of cell shape during the cell cycle," Results and Problems in Cell Differentiation, vol. 53, pp. 31-73, 2011.

[43] P. K. Hepler, A. Valster, T. Molchan, and J. W. Vos, "Roles for Kinesin and myosin during cytokinesis," Philosophical Transactions of the Royal Society B, vol. 357, no. 1422, pp. 761766, 2002.

[44] M. D. Larrea, F. Hong, S. A. Wander et al., "RSK1 drives p27Kip1 phosphorylation at T198 to promote RhoA inhibition and increase cell motility," Proceedings of the National Academy of Sciences of the United States of America, vol. 106, no. 23, pp. 9268-9273, 2009.

[45] A. Van Opstal, J. J. M. Bijvelt, C. Margadant, and J. Boonstra, "Role of signal transduction and actin in G1 phase progression," Advances in Enzyme Regulation, vol. 45, pp. 186-200, 2005.

[46] N. Kaji, A. Muramoto, and K. Mizuno, "LIM kinase-mediated cofilin phosphorylation during mitosis is required for precise spindle positioning," Journal of Biological Chemistry, vol. 283, no. 8, pp. 4983-4992, 2008.

[47] F. F. Hsu, T. Y. Lin, J. Y. Chen, and S. Y. Shieh, "P53-mediated transactivation of LIMK2b links actin dynamics to cell cycle checkpoint control," Oncogene, vol. 29, no. 19, pp. 2864-2876, 2010.

[48] M. Davila, D. Jhala, D. Ghosh, W. E. Grizzle, and R. Chakrabarti, "Expression of LIM kinase 1 is associated with reversible G1/S phase arrest, chromosomal instability and prostate cancer," Molecular Cancer, vol. 6, article 40, 2007.

[49] A. Amiri, F. Noei, T. Feroz, and J. M. Lee, "Geldanamycin anisimycins activate rho and stimulate rho- and ROCKdependent actin stress fiber formation," Molecular Cancer Research, vol. 5, no. 9, pp. 933-942, 2007.

[50] Y.-P. Ho, C.-W. Kuo, Y.-T. Hsu et al., " $\beta$-Actin is a downstream effector of the PI3K/AKT signaling pathway in myeloma cells," Molecular and Cellular Biochemistry, vol. 348, no. 1-2, pp. 129139, 2011.

[51] H. Chen, J. Bai, J. Ye et al., "JWA as a functional molecule to regulate cancer cells migration via MAPK cascades and F-actin cytoskeleton," Cellular Signalling, vol. 19, no. 6, pp. 13151327, 2007.

[52] E. H. J. Danen, P. Sonneveld, A. Sonnenberg, and K. M. Yamada, "Dual stimulation of Ras/Mitogen-activated protein kinase and RhoA by cell adhesion to fibronectin supports growth factor-stimulated cell cycle progression," Journal of Cell Biology, vol. 151, no. 7, pp. 1413-1422, 2000.

[53] B. Geiger, A. Bershadsky, R. Pankov, and K. M. Yamada, "Transmembrane extracellular matrix-cytoskeleton crosstalk," Nature Reviews Molecular Cell Biology, vol. 2, no. 11, pp. 793805, 2001.

[54] M. Maekawa, T. Ishizaki, S. Boku et al., "Signaling from Rho to the actin cytoskeleton through protein kinases ROCK and LIM-kinase," Science, vol. 285, no. 5429, pp. 895-898, 1999.

[55] E. D. Schejter, "Actin organization in the early Drosophila embryo," Novartis Foundation Symposium, vol. 269, pp. 127138, 2005.

[56] K. Schwarzerova, Z. Vondrakova, L. Fischer et al., "The role of actin isoforms in somatic embryogenesis in Norway spruce," BMC Plant Biology, vol. 10, article 89, 2010.

[57] D. L. Kropf, S. K. Berge, and R. S. Quatrano, "Actin localization during fucus embryogenesis," Plant Cell, vol. 1, no. 2, pp. 191200, 1989.

[58] M. Ma, L. Zhou, X. Guo et al., "Decreased cofilin1 expression is important for compaction during early mouse embryo development," Biochimica et Biophysica Acta, vol. 1793, no. 12, pp. 1804-1810, 2009.

[59] J. R. Bamburg and G. S. Bloom, "Cytoskeletal pathologies of Alzheimer disease," Cell Motility and the Cytoskeleton, vol. 66, no. 8, pp. 635-649, 2009.

[60] R. C. Davis, R. Furukawa, and M. Fechheimer, "A cell culture model for investigation of Hirano bodies," Acta Neuropathologica, vol. 115, no. 2, pp. 205-217, 2008.

[61] L. S. Minamide, A. M. Striegl, J. A. Boyle, P. J. Meberg, and J. R. Bamburg, "Neurodegenerative stimuli induce persistent ADF/cofilin-actin rods that disrupt distal neurite function," Nature Cell Biology, vol. 2, no. 9, pp. 628-636, 2000.

[62] M. E. Velasco, M. A. Smith, S. L. Siedlak, A. Nunomura, and G. Perry, "Striation is the characteristic neuritic abnormality in Alzheimer disease," Brain Research, vol. 813, no. 2, pp. 329333, 1998

[63] M. T. Maloney and J. R. Bamburg, "Cofilin-mediated neurodegeneration in Alzheimer's disease and other amyloidopathies," Molecular Neurobiology, vol. 35, no. 1, pp. 21-43, 2007.

[64] P. Garg, R. Verma, L. Cook et al., "Actin-depolymerizing factor cofilin-1 is necessary in maintaining mature podocyte architecture," Journal of Biological Chemistry, vol. 285, no. 29, pp. 22676-22688, 2010.

[65] P. Mundel, J. Reiser, A. Z. M. Borja et al., "Rearrangements of the cytoskeleton and cell contacts induce process formation during differentiation of conditionally immortalized mouse podocyte cell lines," Experimental Cell Research, vol. 236, no. 1, pp. 248-258, 1997.

[66] W. E. Smoyer and P. Mundel, "Regulation of podocyte structure during the development of nephrotic syndrome," Journal of Molecular Medicine, vol. 76, no. 3-4, pp. 172-183, 1998.

[67] C. Faul, K. Asanuma, E. Yanagida-Asanuma, K. Kim, and P. Mundel, "Actin up: regulation of podocyte structure and function by components of the actin cytoskeleton," Trends in Cell Biology, vol. 17, no. 9, pp. 428-437, 2007.

[68] P. Mundel and J. Reiser, "Proteinuria: an enzymatic disease of the podocyte," Kidney International, vol. 77, no. 7, pp. 571$580,2010$.

[69] D. Kerjaschki, "Caught flat-footed: podocyte damage and the molecular bases of focal glomerulosclerosis," Journal of Clinical Investigation, vol. 108, no. 11, pp. 1583-1587, 2001.

[70] S. Ashworth, B. Teng, J. Kaufeld et al., "Cofilin-1 inactivation leads to proteinuria - studies in zebrafish, mice and humans," PLoS ONE, vol. 5, no. 9, Article ID e12626, pp. 1-10, 2010.

[71] J. M. Kaplan, S. H. Kim, K. N. North et al., "Mutations in ACTN4, encoding $\alpha$-actinin-4, cause familial focal segmental glomerulosclerosis," Nature Genetics, vol. 24, no. 3, pp. 251256, 2000

[72] M. Kestilä, U. Lenkkeri, M. Männikkö et al., "Positionally cloned gene for a novel glomerular protein-Nephrin-is mutated in congenital nephrotic syndrome," Molecular Cell, vol. 1, no. 4, pp. 575-582, 1998.

[73] N. Boute, O. Gribouval, S. Roselli et al., "NPHS2, encoding the glomerular protein podocin, is mutated in autosomal recessive steroid-resistant nephrotic syndrome," Nature Genetics, vol. 24, no. 4, pp. 349-354, 2000.

[74] J. Y. Rao and N. Li, "Microfilament actin remodeling as a potential target for cancer drug development," Current Cancer Drug Targets, vol. 4, no. 4, pp. 345-354, 2004.

[75] T. T. Bonello, J. R. Stehn, and P. W. Gunning, "New approaches to targeting the actin cytoskeleton for chemotherapy," Future Medicinal Chemistry, vol. 1, no. 7, pp. 1311-1331, 2009. 
[76] D. H. Lee, G. B. Iwanski, and N. H. Thoennissen, "Cucurbitacin: ancient compound shedding new light on cancer treatment," TheScientificWorldJournal, vol. 10, pp. 413-418, 2010.

[77] D. A. Knecht, R. A. LaFleur, A. W. Kahsai, C. E. Argueta, A. B. Beshir, and G. Fenteany, "Cucurbitacin I Inhibits cell motility by indirectly interfering with actin dynamics," PLoS ONE, vol. 5, no. 11, Article ID e14039, 2010.

[78] T. Tannin-Spitz, S. Grossman, S. Dovrat, H. E. Gottlieb, and M. Bergman, "Growth inhibitory activity of cucurbitacin glucosides isolated from Citrullus colocynthis on human breast cancer cells," Biochemical Pharmacology, vol. 73, no. 1, pp. 56-67, 2007.

[79] D. Yin, N. Wakimoto, H. Xing et al., "Cucurbitacin B markedly inhibits growth and rapidly affects the cytoskeleton in glioblastoma multiforme," International Journal of Cancer, vol. 123, no. 6, pp. 1364-1375, 2008.

[80] K. L. K. Duncan, M. D. Duncan, M. C. Alley, and E. A. Sausville, "Cucurbitacin E-induced disruption of the actin and vimentin cytoskeleton in prostate carcinoma cells," Biochemical Pharmacology, vol. 52, no. 10, pp. 1553-1560, 1996.

[81] K. A. El Sayed, M. A. Khanfar, H. M. Shallal et al., "Latrunculin $\mathrm{A}$ and its C-17-O-carbamates inhibit prostate tumor cell invasion and HIF-1 activation in breast tumor cells," Journal of Natural Products, vol. 71, no. 3, pp. 396-402, 2008.

[82] J. I. Chao and H. F. Liu, "The blockage of survivin and securin expression increases the cytochalasin B-induced cell death and growth inhibition in human cancer cells," Molecular Pharmacology, vol. 69, no. 1, pp. 154-164, 2006.

[83] H. Takeuchi, G. Ara, E. A. Sausville, and B. Teicher, "Jasplakinolide: interaction with radiation and hyperthermia in human prostate carcinoma and Lewis lung carcinoma," Cancer Chemotherapy and Pharmacology, vol. 42, no. 6, pp. 491-496, 1998.

[84] K. Nagata-Ohashi, Y. Ohta, K. Goto et al., "A pathway of neuregulin-induced activation of cofilin-phosphatase Slingshot and cofilin in lamellipodia," Journal of Cell Biology, vol. 165, no. 4, pp. 465-471, 2004.

[85] Y. J. Lee, T. J. Sheu, and P. C. Keng, "Enhancement of radiosensitivity in $\mathrm{H} 1299$ cancer cells by actin-associated protein cofilin," Biochemical and Biophysical Research Communications, vol. 335, no. 2, pp. 286-291, 2005.

[86] P. Hotulainen, E. Paunola, M. K. Vartiainen, and P. Lappalainen, "Actin-depolymerizing factor and cofilin-1 play overlapping roles in promoting rapid F-actin depolymerization in mammalian nonmuscle cells," Molecular Biology of the Cell, vol. 16, no. 2, pp. 649-664, 2005.

[87] N. Zebda, O. Bernard, M. Bailly, S. Welti, D. S. Lawrence, and J. S. Condeelis, "Phosphorylation of ADF/cofilin abolishes EGFinduced actin nucleation at the leading edge and subsequent lamellipod extension," Journal of Cell Biology, vol. 151, no. 5, pp. 1119-1127, 2000.

[88] B. V. McConnell, K. Koto, and A. Gutierrez-Hartmann, "Nuclear and cytoplasmic LIMK1 enhances human breast cancer progression," Molecular Cancer, vol. 10, article 75, 2011.

[89] D. H. Vlecken and C. P. Bagowski, "LIMK1 and LIMK2 are important for metastatic behavior and tumor cell-induced angiogenesis of pancreatic cancer cells," Zebrafish, vol. 6, no. 4, pp. 433-439, 2009.

[90] K. Borensztajn, M. P. Peppelenbosch, and C. A. Spek, "Coagulation Factor Xa inhibits cancer cell migration via LIMK1mediated cofilin inactivation," Thrombosis Research, vol. 125, no. 6, pp. e323-e328, 2010.
[91] T. Ahmed, K. Shea, J. R. W. Masters, G. E. Jones, and C. M. Wells, "A PAK4-LIMK1 pathway drives prostate cancer cell migration downstream of HGF," Cellular Signalling, vol. 20, no. 7, pp. 1320-1328, 2008.

[92] C. T. Yap, T. I. Simpson, T. Pratt, D. J. Price, and S. K. Maciver, "The motility of glioblastoma tumour cells is modulated by intracellular cofilin expression in a concentration-dependent manner," Cell Motility and the Cytoskeleton, vol. 60, no. 3, pp. 153-165, 2005.

[93] J. Van Rheenen, X. Song, W. Van Roosmalen et al., "EGFinduced PIP2 hydrolysis releases and activates cofilin locally in carcinoma cells," Journal of Cell Biology, vol. 179, no. 6, pp. 1247-1259, 2007. 

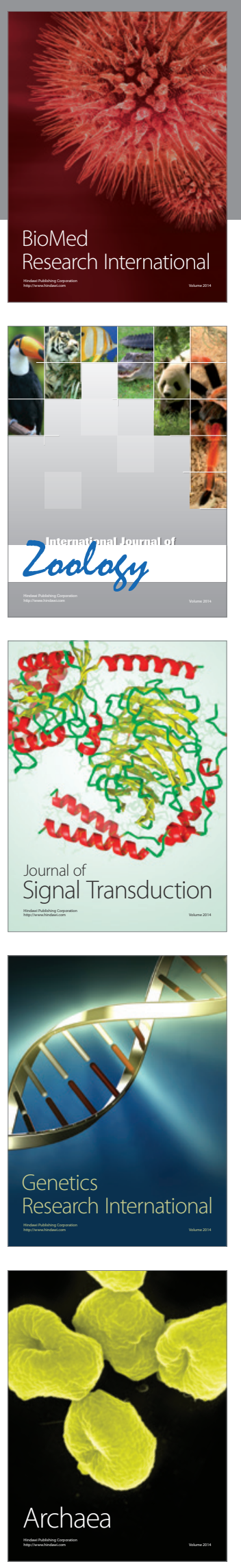
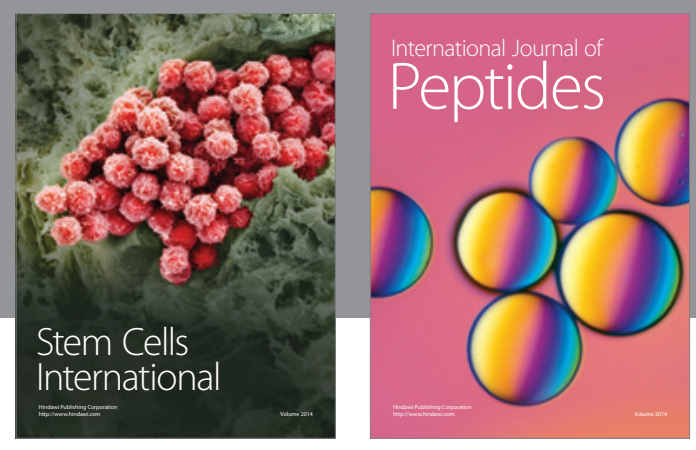

Submit your manuscripts at

http://www.hindawi.com
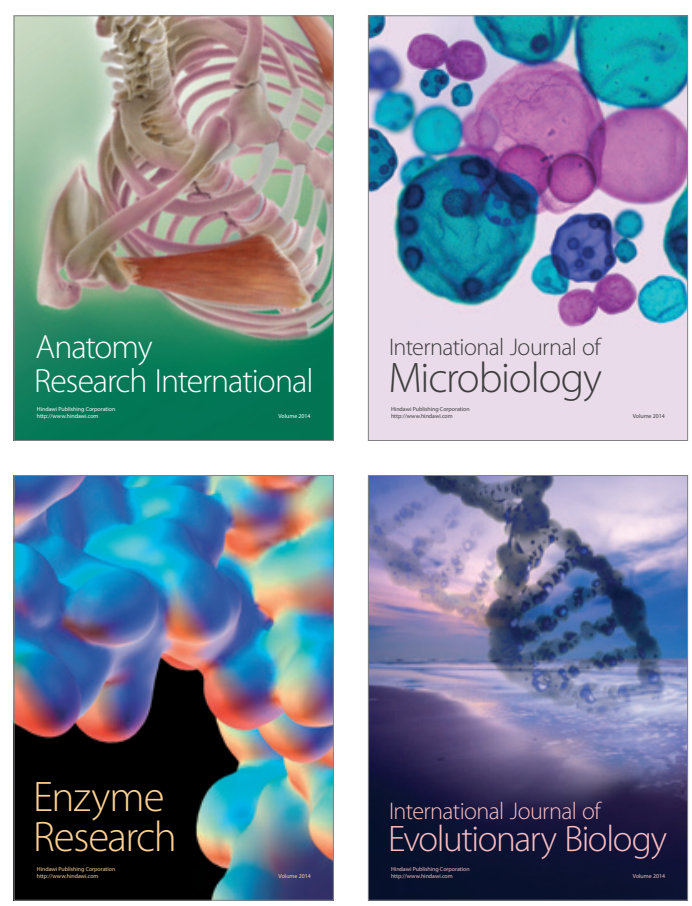
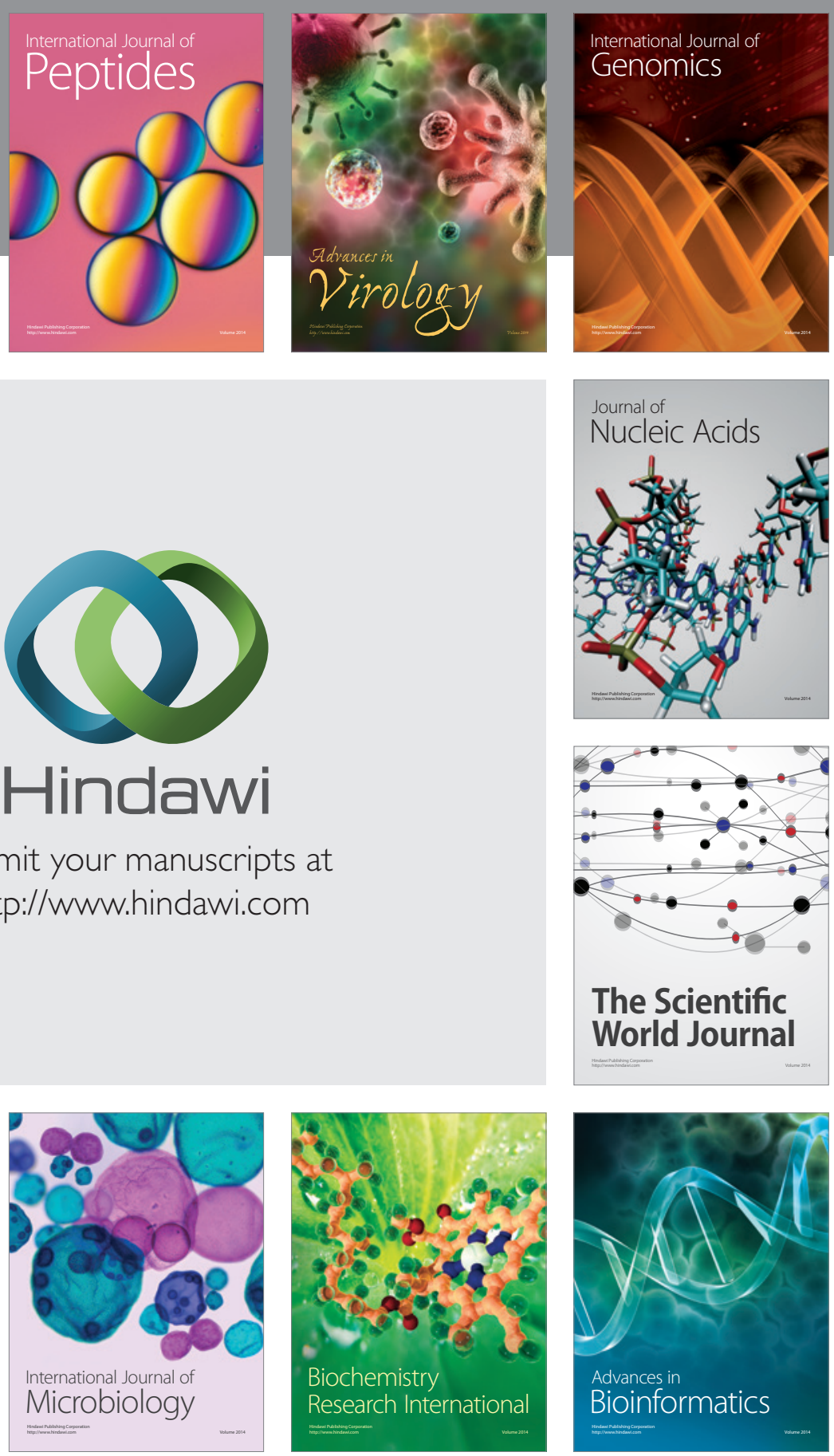

The Scientific World Journal
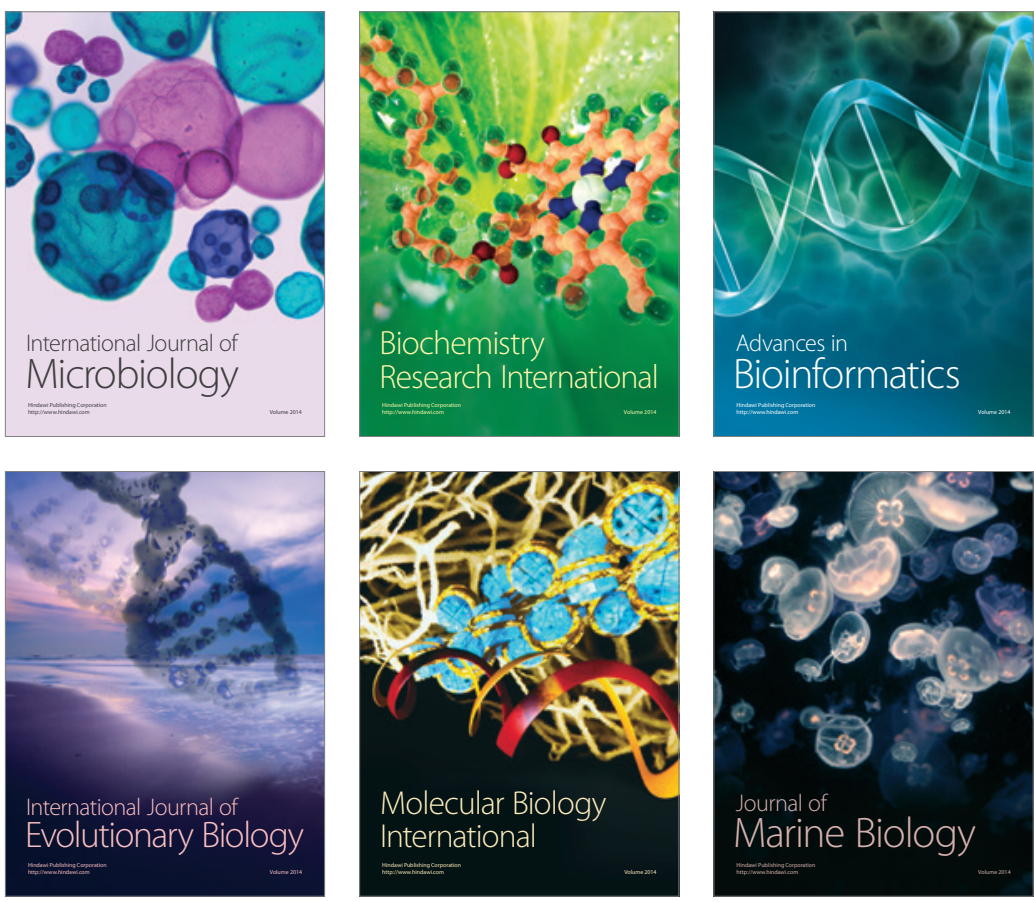